\title{
Recovering Cannibalism in Architecture with a Return to Cyclopean Masonry
}

\author{
Brandon Clifford ${ }^{1}$ - Wes McGee ${ }^{1}$. \\ Mackenzie Muhonen ${ }^{1}$
}

\begin{abstract}
Each year, the United States discards 375 million tons of concrete construction debris to landfills. But this is a new paradigm. Past civilizations cannibalized their constructions to produce new architectures. This paper interrogates one cannibalistic methodology from the past known as Cyclopean Masonry in order to translate this valuable method into a contemporary digital procedure. The work contextualizes the techniques of this method and situates them into procedural recipes which can be applied in contemporary construction. A full-scale prototype utilizes the described method; demolition debris is gathered, scanned, and processed through the virtual algorithm. Each rubble unit is then minimally carved by a robotic arm and set to compose a new architecture from discarded rubble debris. The prototype merges ancient construction thinking with advanced digital procedures. It poses material cannibalism as a means of combatting excessive construction waste generation.
\end{abstract}

Keywords Digital fabrication · Cyclopean masonry · Computation ·

Algorithm · Robotics · Stone

\section{Introduction: Ancient Knowledge, Digital Techniques}

The knowledge embedded in centuries-old stone-cutting techniques and the architectural potentials they produce hold unique opportunities in the context of digital design and fabrication. As a research agenda, Cyclopean Cannibalism tests this pairing. This paper outlines the context, development, and prototyping of the new tectonic territory of material cannibalism. Cyclopean Cannibalism clashes with the mythology of sameness consuming sameness with the realism of rampant

Brandon Clifford

1 Jamaica Plain, USA

Birkhäuser 
urbanism and environmental destruction. As a hypothesis, it argues for the ingestion of waste materials to generate new structures. This postulation links two islands of knowledge-ancient stone-fitting techniques and contemporary computational tools. It poses cyclopean masonry as a living system that ingests urban debris to generate new, flexible building systems. Technique is prioritized over final form, with mass-customized units robotically carved to generate a single system.

While this concept of cannibalization is not standard practice today, the groundwork has been laid to tackle these motivations in the contemporary context. In his text Radical Reconstruction, Lebbeus Woods positions this concept. His drawings operate under the premise of "reincarnation out of willful destruction" (Woods 1997). Material debris is re-adapted to become entire buildings or armatures on existing structures. This act of re-consuming becomes a character trait in the resultant architectures. The appropriated debris embedded in his drawings-rubble left over from warfare, economic stagnation, and earthquakes-raise questions on the entrenched, past experiences of readapted materials. It questions what these memories carry into the reassembled structure.

Architects have recently taken up Woods's assertions, operating within the framework of digital fabrication. Greg Lynn and the team of Gramazio Kohler have expanded our vocabulary of design uncertainty through advances in scanning and robotics. Greg Lynn's "Blob Wall" (Lynn 2005) employed 'reinvented,' hollow plastic as robotically molded bricks, or individual components assembled to form a 'blob' wall. This inventive project reconsidered the potentials of selectively carving complex intersections via robotics. This process knows the geometries prior to the digital Boolean operation, illuminating the problematics of compacting the units to ensure collisions occur. Gramazio Kohler's "Endless Wall" (Helm et al. 2012) also utilized robotics in the construction process to assemble individualized components into a single wall. While this project contributes to resolving unknown conditions through scanning, it maintains stacking without indexing or carving. These explorations underscore the burgeoning confluence between construction processes, robotics and masonry.

Recent advances in robotics and scanning allow us to dislodge the technique from its roots within the contemporary context of economy of labor. They provide an original framework, upon which we can explore new treatments to demolition debris. While there has been significant interest in the development and adaptation of robotic fabrication techniques to architectural applications, it is the more recent move toward implementing adaptive processes that holds the most potential to disrupt the typical digital fabrication paradigm. The incorporation of sensor feedback into a production process can occur at multiple levels. A typical sensing system might include a one or two-dimensional laser, or a three-dimensional timeof-flight camera such as the Microsoft Kinect (Dal Mutto 2012).

Industrial manufacturing processes often use a variety of sensing and gauging techniques to insure part accuracy, especially in processes where tool wear or variability in work holding could compromise the desired tolerances. By integrating the sensing process tightly within the production workflow, this can be extended to the concept of "Adaptive Part Variation" (Vasey 2014), whereby sensors are utilized to provide real time feedback to robotic fabrication and assembly processes. 
This feedback can be used to make online corrections to the geometry of future components to adapt to deviations between a master digital model and a constantly updated as built condition. Within the context of mobile robotics, sensors can be used to provide feature-based localization, for example in situ assembly processes utilizing mobile robot manipulators (Dorfler 2016).

Cyclopean Cannibalism is a multi-temporal and tectonic research endeavor. These layers require unpacking before dissecting the findings from the wall prototype as exhibited at the 2017 Seoul Biennale of Architecture and Urbanism: Imminent Commons (Zaera-Polo and Anderson 2017). A look at examples of Cyclopean Masonry and the mythology that surrounds them will first frame the conceptualization of the research. This component focuses first on dry-stacking and cyclopean masonry as a typology, then shifts to Inkan stone works as exemplary cases of cyclopean masonry. This includes the mythology that abounds their construction. Through these Inka techniques, debris can be cannibalized to generate cyclopean masonry structures. Following this conceptual framing, the paper then offers a contextual positioning for the use of Cyclopean Cannibalism today and experiments with this proposal at full scale.

\section{On Mythology, or Cyclopean Masonry}

Cyclopean masonry (Fig. 1) refers to masonry structures so massive, precise, cryptic, and irrational, that the only conceivable builder was a primordial race of giants we know of as Cyclops from Hesoid's Theogony (Hesiod 1953). These giants are the authors of megalithic stone works. Massive stones are assembled dry and composed into a cohesive composition. Given their precise assembly, these works project the illusion that they are squeezed together by giants.

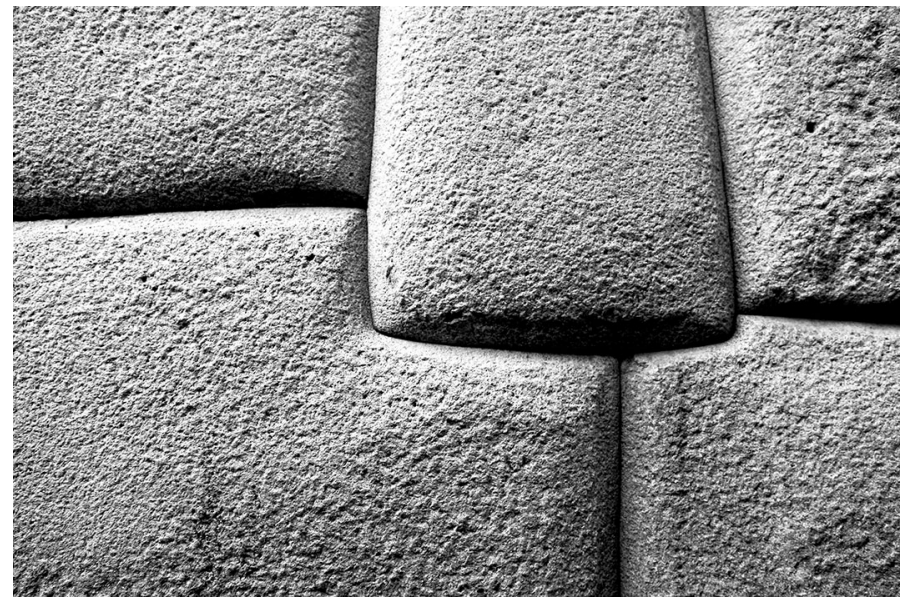

Fig. 1 Cyclopean Masonry-Inka Roca, Cusco Perú c. 1350 CE 
But while the term Cyclopean is anchored in Mediterranean architectural history, the practice emerges across the globe. Though civilizations had not communicated with each other, a striking similarity between their constructions is haunting (Fig. 2). Each of these cultures developed an ingenuity surrounding the recycling of stone. This ingenuity is predicated on a few shared resources. One of these being stone, but most deterministic to their work are hammerstones (Fig. 3). "The Inka referred to the working of finely joined masonry as canincakuchini, which is derived from the verb kanini (canini), meaning to bite or nibble." (Dean 2010: 76). Aside from the byproduct of precision nibbling with hammerstones, this method of stone dressing also ensured quarrying was a limited option. Jean-Pierre Protzen describes that "[i]n the quarries of Kachiqhata, the $\operatorname{In}[\mathrm{k}] \mathrm{a}$ did not practice quarrying in the technical sense. The stone was neither split off a rock face nor detached from bedrock... The quarrymen simply went through gigantic rockfalls, carefully selecting raw blocks that met their specifications" (Protzen 1993: 165). This meant energy was displaced into searching for the correct shape to fill a desired gap. This resource and technology ensures a motivation that results in placing the largest stone imaginable, as to limit searches and carving.

Past civilizations were also adroit in adapting previously built structures into transformed environments. These methods of re-appropriation reduced waste and transportation efforts, particularly in stone works. The Inka Empire was especially adept in managing developmental waste. The stonemasons of this civilization drew from found stone debris as material and the landscape as formal template. The stone works expressed contextual immediacy and resourcefulness.

This method employed by the Inka and other civilizations speaks to the ingenuity embedded in the cyclopean system. Stones were sourced, selected, templated, and minimally carved in situ to respond to site constraints. This living procedural
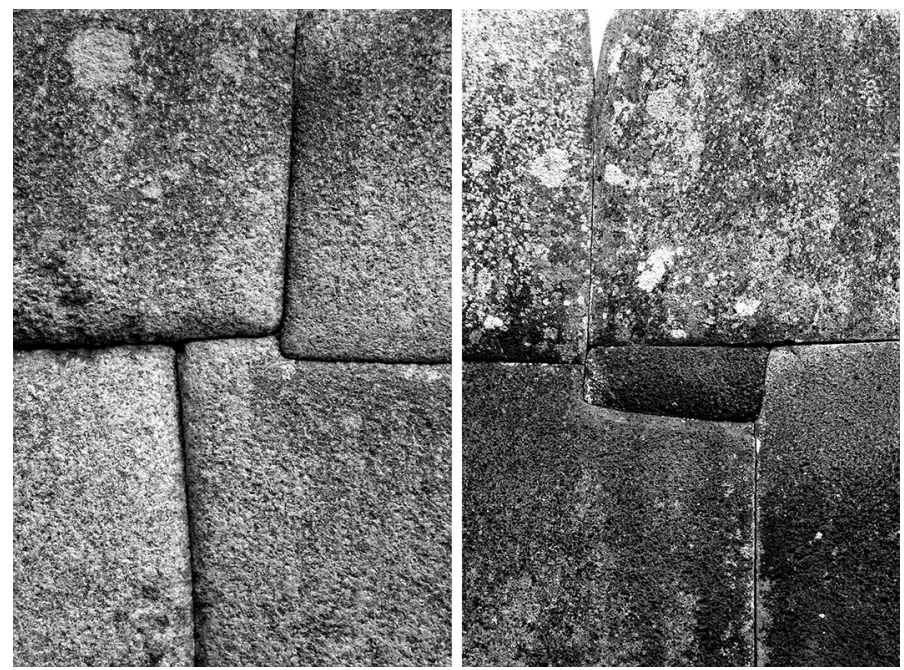

Fig. 2 A comparison image of Inka (left) and Rapanui (right) Cyclopean Masonry. While these cultures had not communicated with each other, their resultant architectures are strikingly similar 
Fig. 3 Diagram of a hammerstone carving

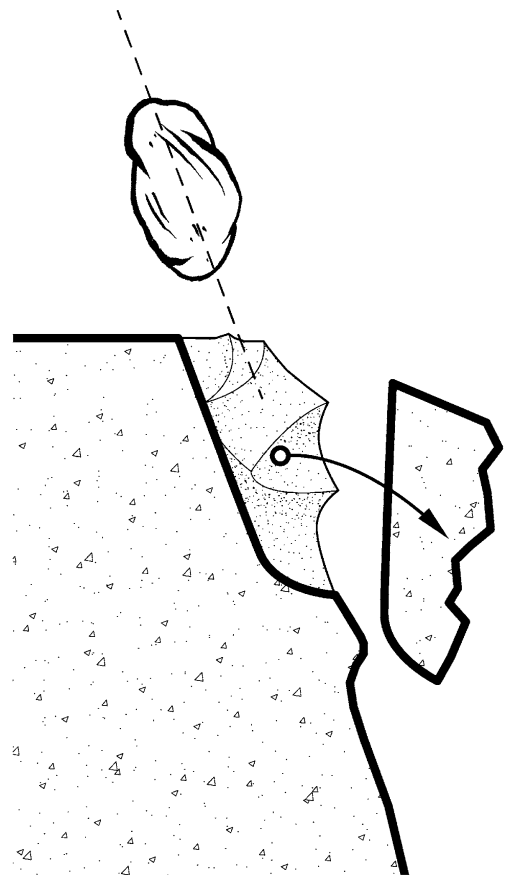

method ensured precision architecture, but it also allowed for the recycling and cannibalizing of architecture. The results are apparently cryptic, but they mirror the contemporary potentials offered by digital production. Not only can these methods be translated into digital algorithms for aggregation, but potentials of live feedback into the system offered by robotic scanning point to a future of automated recycling.

\section{On Realism, or Material Cannibalism}

The discussion on material reuse can stray into the territory of violence. Material cannibalism emphasizes the violent, haptic gradient of reuse. In this sense, the term cannibalism is used to frame the research as both verb and noun. The term does not refer to the common use of cannibal as human consuming human. Instead, it references inanimate matter consuming itself, or its own likeness. This cannibalism is an inhuman one, in which a material sameness consumes its own likeness. It refers to upcycling, a material re-adaptation. The intent is not to romanticize barbarity, but to distill its tectonic qualities. Cannibalism, through this repackaging, is reinterpreted as an architectural mindset, a material methodology. And, while unique to our contemporary practice of architecture, is nothing new. For instance, Saint Peter's Basilica in the Vatican cannibalized stones from Rome's Colosseum. "For most of the Middle Ages and early Renaissance the Colosseum was not so much a monument as a quarry." (Hopkins and Beard 2005: 160). 
This knowledge of material reuse has been neglected since modernism and industrialization with a focus placed on single stream material delivery. However, a number of challenges confront the immediate testing of this reuse. Materials of expediency and efficiency are often prioritized over tectonics of durability. These materials of expediency are privileged because they match the rapid rate of global construction and are typically more budget-friendly. With these fast and more affordable materials, cities are developing at an unprecedented rate. By 2050, the majority of the world's population will live in cities (Harvey 2014).

Today, cities generate construction waste faster than they can responsibly and sustainably control. The daily waste that humans generate-packaging, food, paper, etc. - totals about 254 million tons a year in municipalities (U.S. EPA 2015). This is the visible, most immediate waste humans generate. Meanwhile, the construction waste generated far surpasses this number, but remains invisible. Construction debris is moved around the city in trucks and trains, out of sight. This quantity doubles daily waste, about 534 tons a year. Or, put in perspective, "[t]he average person in the United States throws away their body weight in rubbish every month." (Hoornweg et al. 2013). Meaning, the construction industry tosses two body weight bags per month on behalf of each person in the US. Of this construction debris that is generated, the vast majority is non-recyclable concrete. Concrete makes up seventy percent of construction debris, or 375 million tons, each year (U.S. EPA 2016). While some of this concrete is ground up and used as gravel, the cementitious property is lost in this energy intensive process. Today, concrete is not recycled.

This single-life cycle concrete terminates in the landfills. Unlike the past civilizations that re-adapted materials at hand, new resources continue to be fabricated. That which has already been constructed and removed is summarily cast aside. Available, unwanted, even free materials are being buried as environmentally destructive waste in order to excavate dwindling resources. These cities demand a new construction methodology in order to adequately manage the waste they generate.

\section{Practicing Cyclopean Cannibalism}

Cyclopean Cannibalism is an equation of simple addition to resolve these contemporary inconsistencies in architectural practice. This amalgamation proposes to cannibalize and consume rubble to produce a new architecture. In order to test this merging, a manual was written outlining the methodology, mythology, and fabrication of Cyclopean Cannibalism. The Cannibal's Cookbook (Clifford 2017) details recipes for recycled wall fabrications. The recipes overlay mythology with urgent urban necessity. The cookbook distills and offers the recipes from these past civilizations to today's construction industry.

The concepts put forward in The Cannibal's Cookbook were tested through the wall prototype titled Cyclopean Cannibalism at the 2017 Seoul Biennale (Clifford and McGee 2017). In this experiment, large rubble stones are sourced, scanned, and aggregated through an algorithm elaborated upon in the cookbook (Clifford 2017: 
144). The Cyclopean Cannibalism wall maintains a number of the techniques of projection to bridge the 'stone-aged' aggregation method with contemporary possibilities of automated robotic saw cutting. These approaches and techniques that originated as a practical translation have allowed a mystical construction to re-enter the discourse surrounding the relevance of stone construction today.

Cyclopean masonry walls are created through generative design processes with procedural methods and rule-sets. If analyzed stylistically, they are seen as cryptic and illogical, but when viewed through the lens of computation, they tell a different story. Computational approaches are used to find trends in the shape grammars of these walls. These include the ranges of sizes and shapes of stones in a single wall. For instance, some walls are composed of large, but similarly sized stones, while others are made of massive stones filled in with much smaller ones. These metrics help to identify which wall algorithm is the best approach for your stock of rubble. Another metric tested was orientation, whether a stone was more vertical, horizontal, or square in proportion. Similar metrics were applied to test draft angles and the number of neighbors one stone touches. The results of this analysis focus on three primary details that unpack the recipe employed in this wall prototype. These details include bed joints, draft angles, and coursing sequence as seen in Fig. 4.

Fig. 4 Detail from Inka Roca containing draft re-direction, a Utah, and a nub detail

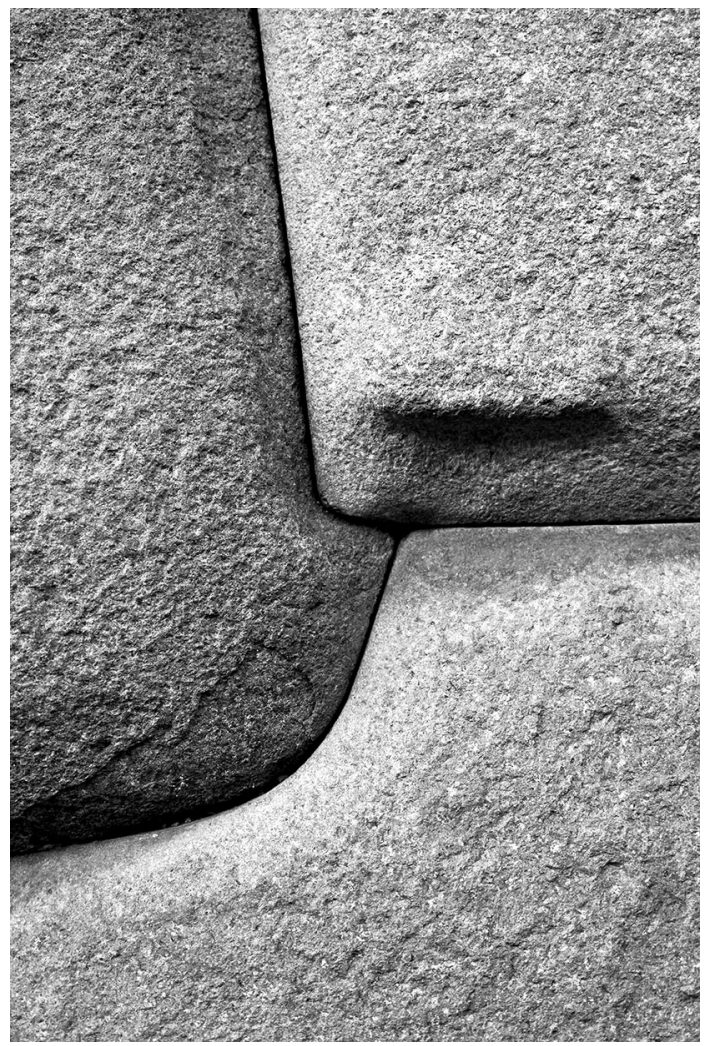




\section{Bed Joints and Utah Details}

In conventional masonry, a bed joint is the horizontal joint. While this makes a great deal of sense with orthogonal masonry, polygonal masonry also contains bed joints. In this case bed joints are the joints that are resisting gravity, even if they are inclined from the horizontal. The Inka would carve the bottoms of the stone intended to be placed and leave the tops uncarved. This is because they know which stones are under a placing stone, but don't yet know the condition above. The result of this directional form is a top profile that is stepped. This stepped profile then becomes an uneven bed joint for the next course (currently describing roughly coursed polygonal masonry). Once set, those tops would be carved in situ to correspond and receive the bed joint of the stones above them. This sequence results in a phenomenon called a Utah shaped stone as seen in Fig. 5. While there are rare examples of upside down Utahs, these are the exception and not the rule. Locating Utahs is helpful in deciphering a wall because they clearly define sequential intention.

\section{Draft Angles}

If bed joints describe the horizontal condition, draft describes the vertical. It is precisely in this difference from true vertical that a wall can further tell its story of assembly. For instance, the lowest course of any wall might have a trapezoidal shaped stone, like a truncated pyramid. This is a stable stone that other stones can reasonably rest up against, from left to right. This trapezoid can be thought of as the inverse of a keystone. It is not the last stone to be laid, but the first. The subsequent stones are not trapezoidal themselves, but become parallelograms, furthering out the

Fig. 5 Diagram of the bed joint setting sequence and the resultant Utah detail

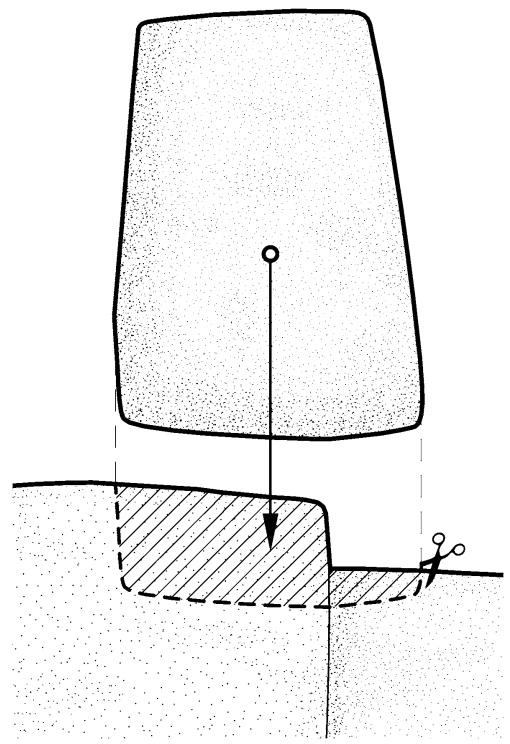


logic until they collide with other systems. An inverted trapezoid (a keystone) closes out the collision. This simple orientation of the side joint can describe the sequence of a wall, but the degree of that angle can also determine whether something is set from above, slid in from the side, or even tilted in. Draft can describe all of the possible assembly directions, often suggesting a narrow range which is most helpful for us. Draft and bed joints co-mingle in a concept we call draft re-direction. This detail typically occurs at a vertex between three stones. A vertical edge might shift its angle from positive to negative when engaging a different stone (Fig. 6), suggesting that a positive draft was helpful to set this stone, but the stone above cannot be slid in from the side, requiring a vertical draft.

\section{Rough Coursing}

The details above help to determine, at the scale of stone-to-stone, the process and method of assembly. A larger scale of analysis is also helpful to consider the macro logic. These cyclopean constructions range from pre-fabricated, coursed constructions to rough coursing, and ultimately fully polygonal (meaning no coursing can be seen). They also occasionally transition from non-coursed to coursed, in an attempt to tame the system. In these conditions, it is occasionally clear that the non-coursed stones are considerably larger, so a correlation between the size of a stone with the logic of its global assembly also aligns. In order to better decipher these mystical walls, a layer of analysis looks at the walls at this scale. This includes coursing, the range of stone sizes, the number of neighbors each stone has, and 'connection' details (Utahs, carved moments edges for custom fit, etc.). Figure 7 demonstrates the results of this analysis.

Fig. 6 Diagram of draft redirection

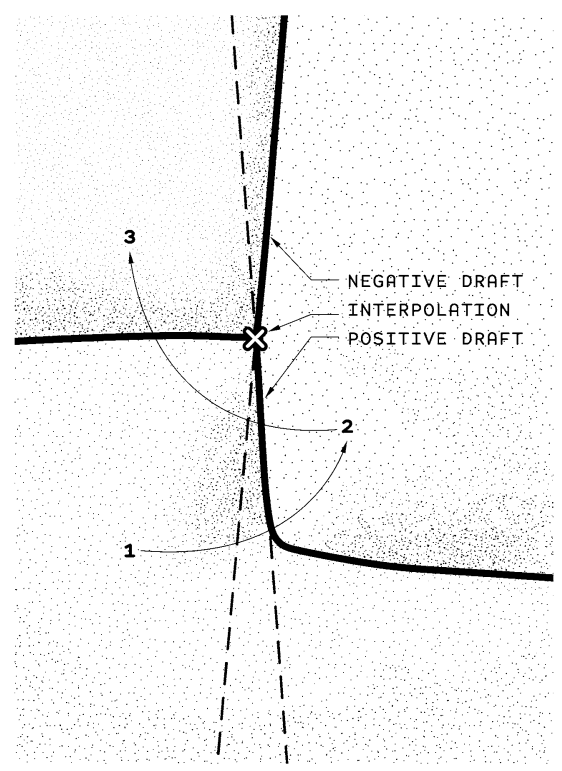




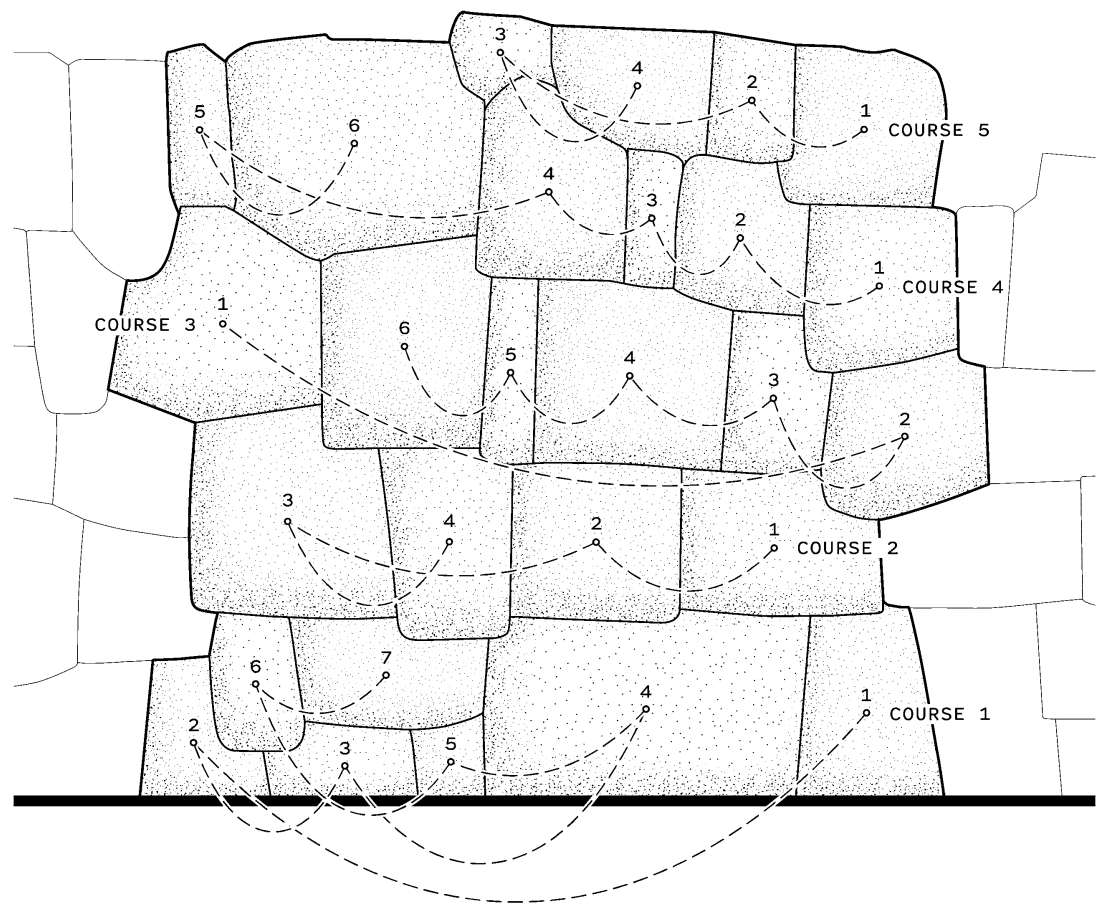

Fig. 7 Coursing sequence diagram, deciphered from Inka Roca, Cusco Perú

\section{The Recipe}

The following recipe was used for the design of the wall prototype. It describes one of the most recognizable typologies of cyclopean masonry. The recipe details the manual sequence of assembly that took place to explicitly outline the code for the computational design prototype to follow.

This recipe consists of large to massive stones that are of roughly the same proportion to each other. (1) Sort the rubble stones into two piles-trapezoids and parallelograms (Fig. 8). (2) Set a series of trapezoid stones in the stable orientation. Make sure to evenly space these stones along the wall, but not adjacent to each other (Fig. 9). (3) Search and select a parallelogram stone that fits nicely in the space adjacent to the previously set stones. Nest that parallelogram into place so it leans

Fig. 8 Sorting of stones types

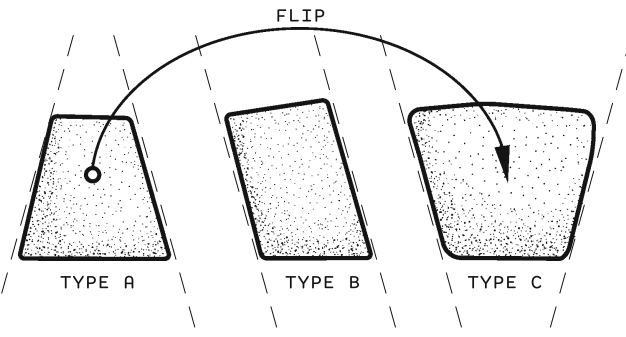




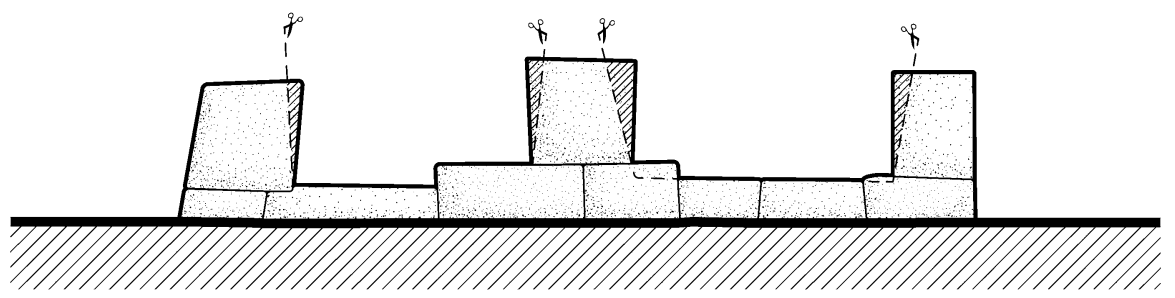

Fig. 9 Set type A stones

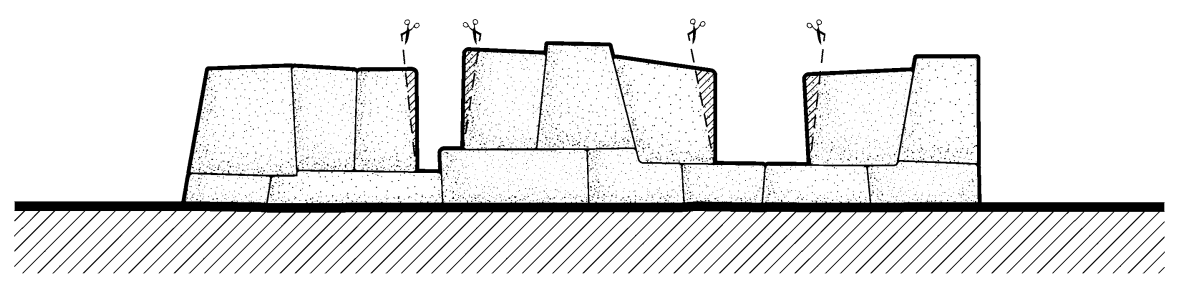

Fig. 10 Set type B stones

against the stable trapezoid (Fig. 10). (4) Continue step 3 until there is space for only one stone in each void. (5) Select a trapezoid stone and set it upside down into the gap left in step 4. This upside-down trapezoid will appear like a keystone (Fig. 11). (6) Continue the process from steps $2-5$ on the next rough coursing, making sure to select stones that always straddle over a vertical joint below. (7) Set the selected stone above the previous course on a stand-off and scribe the geometry of the setting stone onto the bed joint of the course below. Lower this geometry until it gains contact on all surfaces and carve the scribed geometry onto the previously set stones. This will result in a Utah shaped stone below. (8) Lower the offset setting stone down onto the custom carved bed joint below and continue the recipe until the desired wall is met.

\section{The Prototype}

The produced prototype experiments with the recipe previously described and translates that code into a digital procedure capable of recycling abandoned construction rubble. This prototype wall consists of demolition concrete and offcut stone from a variety of construction sites. The design process of this prototype wall begins with a global surface geometry. Rubble is scanned, sorted, digitally placed, carved, and set.

\section{Global Form}

The wall is $6.6 \mathrm{~m}$ long and $2.3 \mathrm{~m}$ tall and weighs $6896 \mathrm{~kg}$. The stones range in thickness from $100 \mathrm{~mm}$ on the ends to $312 \mathrm{~mm}$ in the middle for stability. This variation in thickness helped not only in managing the stability of the wall, but also 


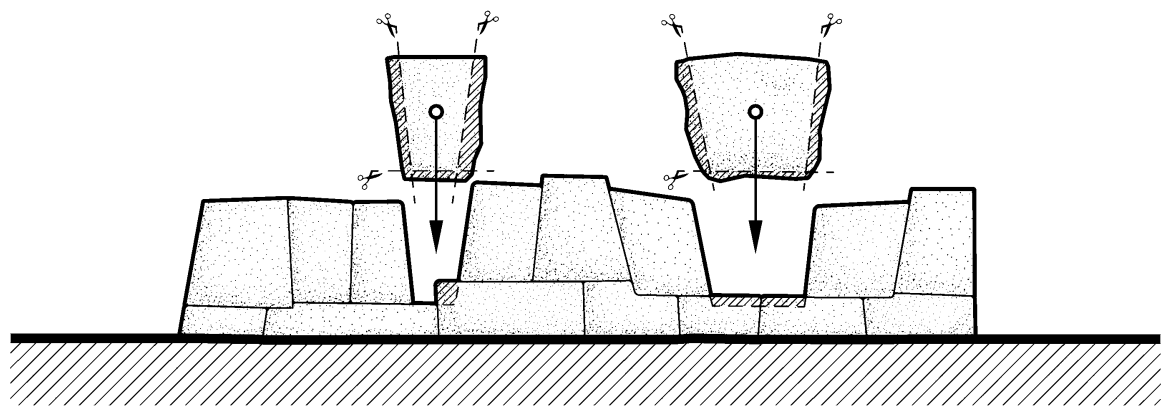

Fig. 11 Set type C stones

in utilizing the range of rubble units stock dimensions. In order to facilitate this varying thickness, a second surface is variably offset to inform the thickness and orientation of each stone. This global form is book-ended by two vertical edges, and an undulating lower curve is adjusted in correspondence with a stability calculation. This undulation produces a surface with compound curvature, which for the Inka and other cyclopean masons would have been difficult to conceive of with their bottom up approach. While their walls were generally vertical (or canted), this digital procedure allows Cyclopean Cannibalism to be virtually set on more complex global forms, a process that progresses many of the cyclopean masonry walls into new geometric territory (Fig. 12).

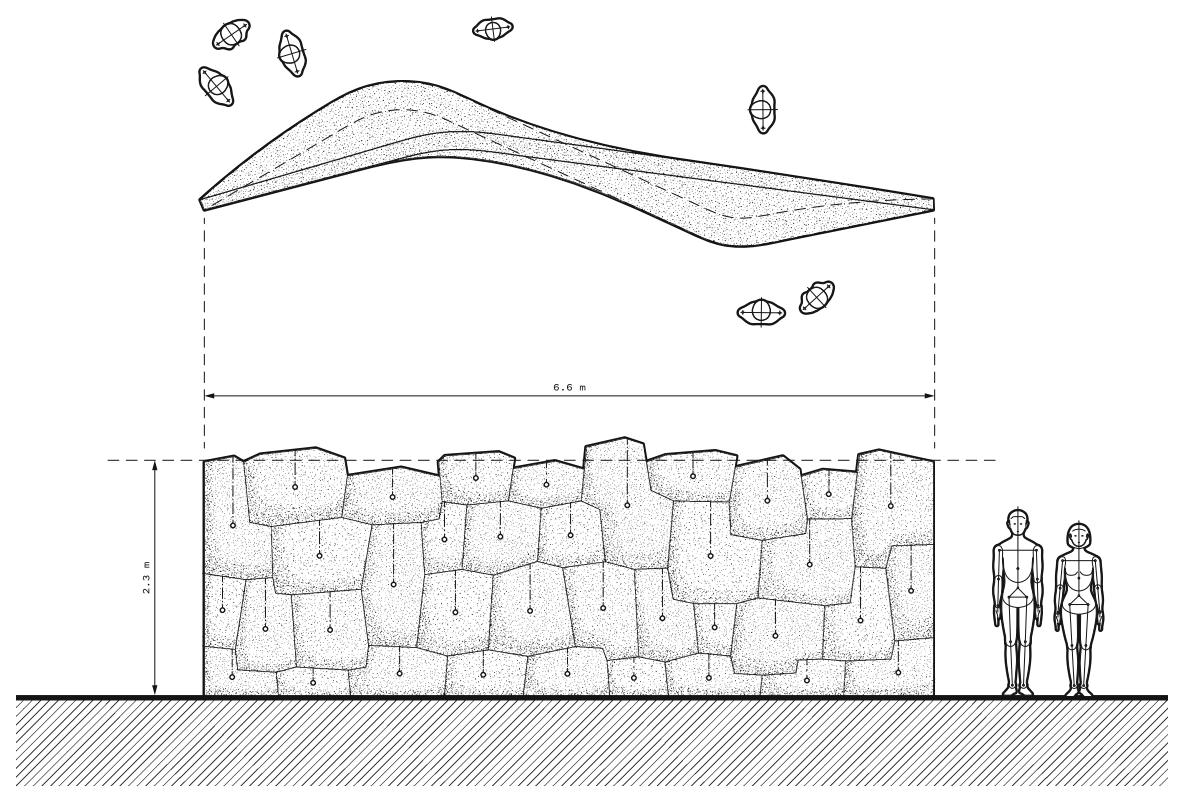

Fig. 12 Plan and elevation of the Cyclopean Cannibalism prototype wall 


\section{Rubble Scanning and Searching}

A selection of demolition rubble is digitally scanned to capture the random geometries. Each stone is set on the chosen back side and the remaining five sides are captured by the scanner. While only five of six sides are received, the flat back is irrelevant to this calculation. This scanning produces a highly detailed point cloud geometry. However, this is thought of as a stock geometry that will be carved from. A recursive algorithm (Clifford 2017: 118) determines the largest four-sided polygon that fits within this digital scan (Fig. 13). It is this polygon that is utilized by the virtual set algorithm. The scanning only facilitates the dimensioning of this maximum polygon search.

\section{Virtual Set}

Once the "pantry" is stocked with virtual polygonal stones, a parametric rig allows a designer to virtually set each stone along the wall following the recipe. This virtual set is driven by the centroid of the polygon that can be moved along the primary global geometry surface (Fig. 14). This point is used to find the closest point on the variable offset surface to establish a planar back in a method similar to one described in 'La Voûte de LeFevre: a Variable-Volume Compression-Only Vault' (Clifford and McGee 2014) and demonstrated in Fig. 15. Because this back face is not carved, the virtual set established that the bounding stock polygon is justified to
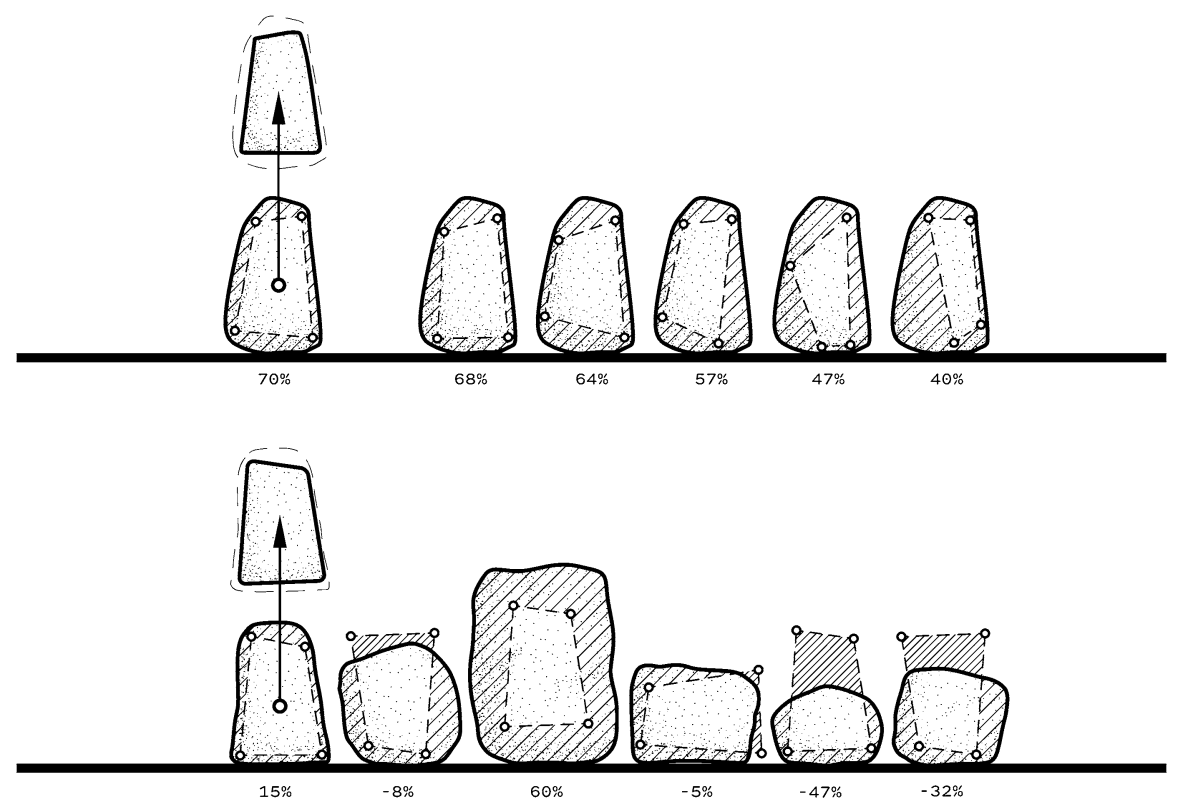

Fig. 13 (Top) Maximum polygon optimization search by measuring positive. (Bottom) Best fit optimization search by measuring negative 


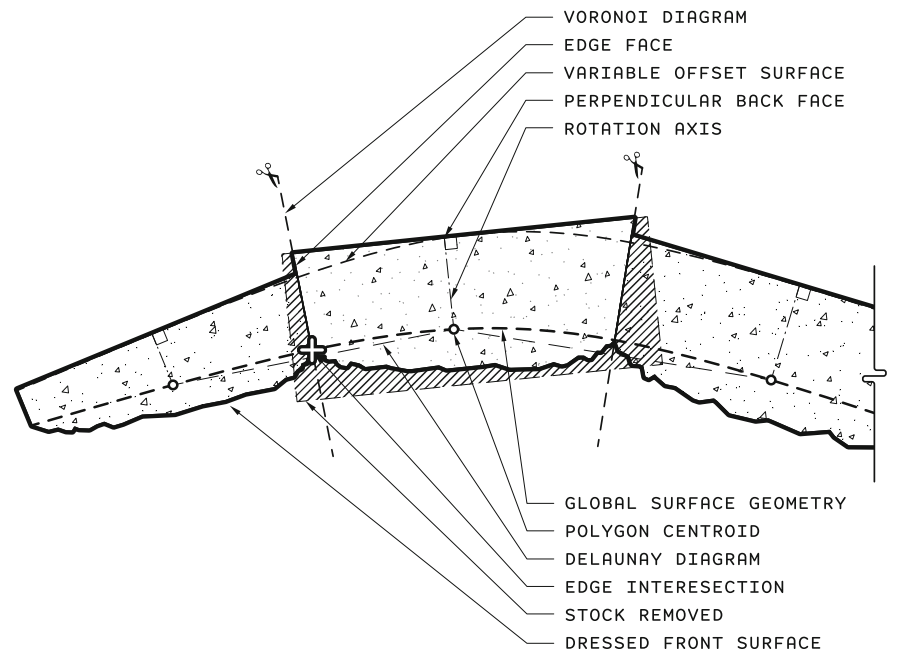

Fig. 14 Detail plan diagram describing the various geometric operations of the virtual set process

Fig. 15 Detail of the back side planar surface slipping detail

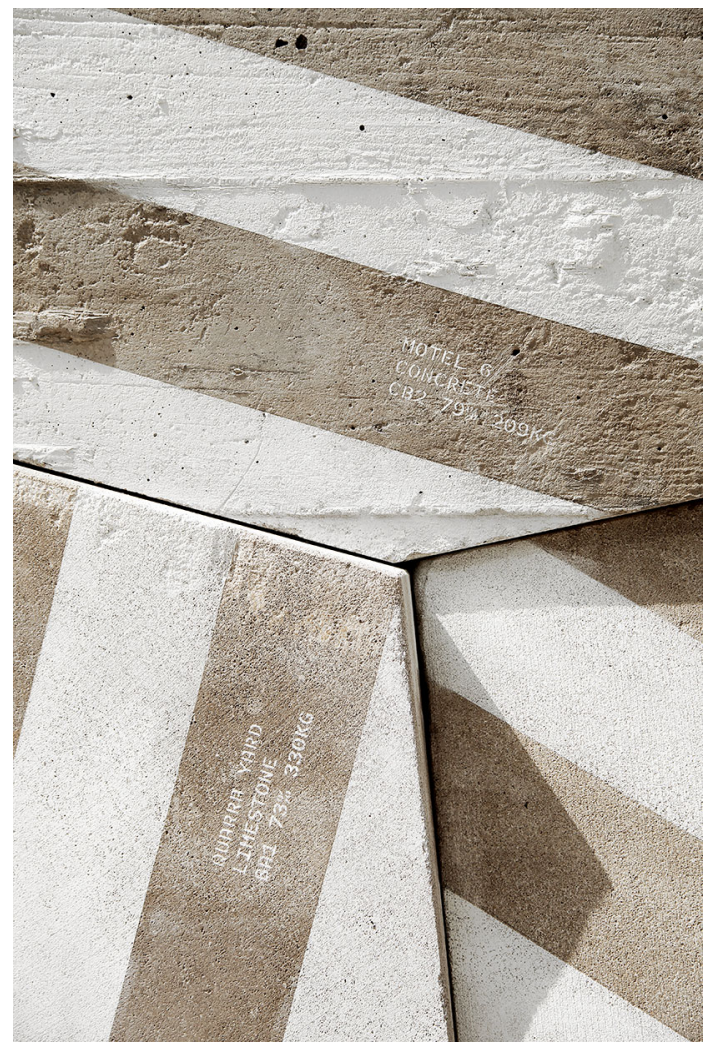




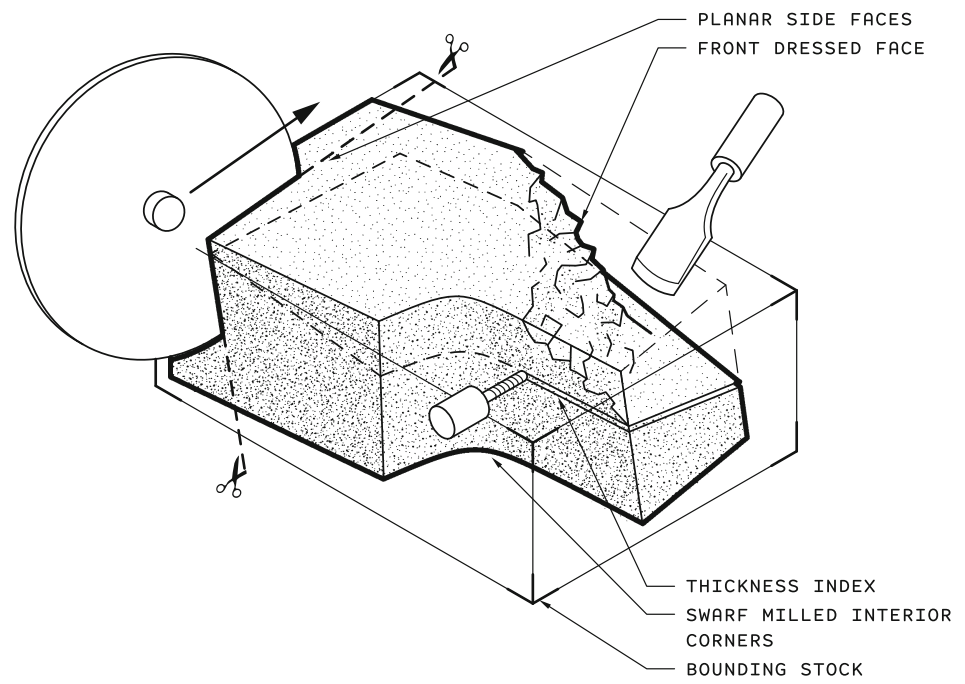

Fig. 16 Diagram of the carving process

Fig. 17 Detail image of the dressed from face after the manual pitching brings the stock thickness back to the intersected index edge

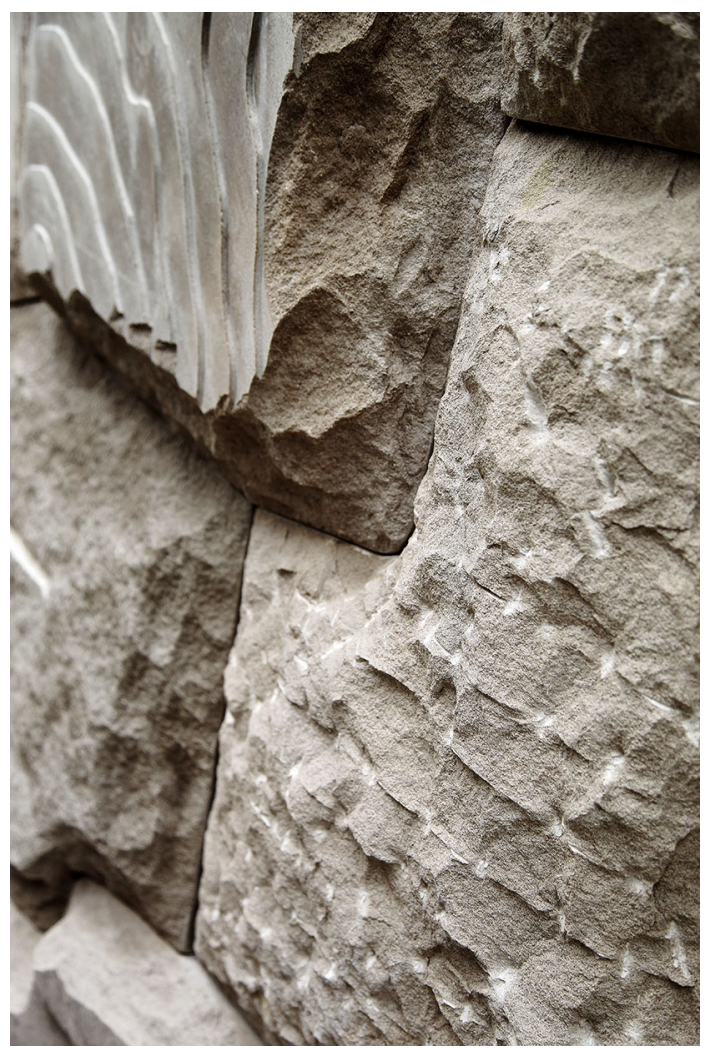


Fig. 18 Cyclopean

Cannibalism prototype wall

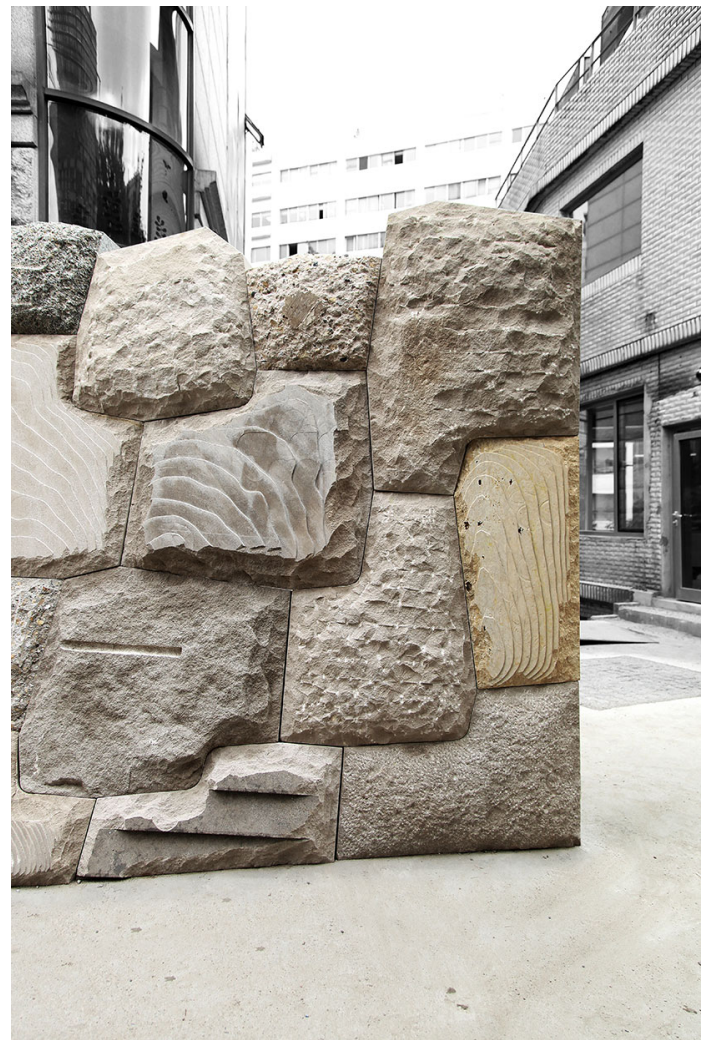

this back planar face. The thickness therefore needs to extend entirely through the primary global geometry surface in order to fully engage the wall thickness.

The other variable available to the designer is rotational orientation. Each polygon is able to rotate around this depth axis in order to set the stone in the orientation that best suits to conditions. When setting, the designer further carves away from the vertical draft angles of adjacent polygons in order to ensure each stone can be set from above. These virtual stones overlap each other until no gap is left between, and the stones are then carved back at these intersections. This process of setting is different from nesting algorithms, which operate under the goal of setting as many geometries into a given bounding condition, by minimizing the residual waste, but maintaining the original geometry of each set part. The algorithm employed in this process differs in that it doesn't minimize the space between parts, but has to remove it entirely, therefore displacing the concept of waste to the amount of material carved from each part. These parts do not retain their original scanned geometry but attempt to reduce the amount of material carved away, resulting in new, but approximately similar polygons to their original rubble shapes. Throughout this virtual set process, a stability check is run iteratively to ensure that each part is not only stable on its own, but also that the current assembly sequence is stable. It is for this reason that a particular assembly sequence is 


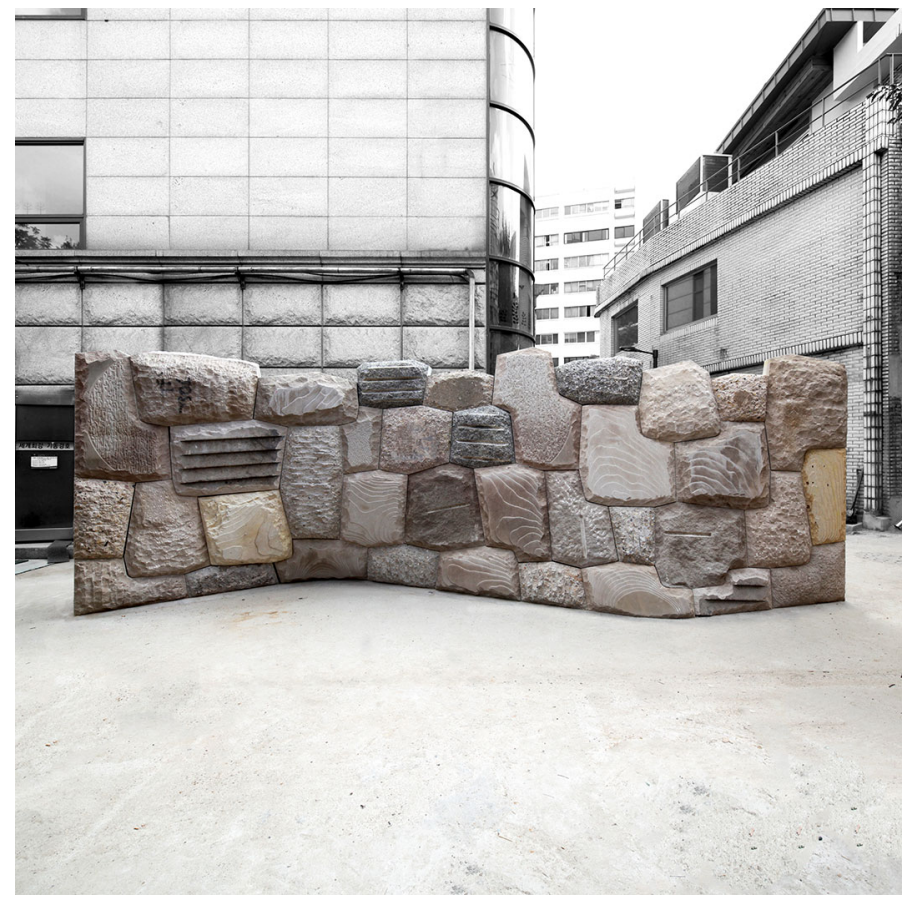

Fig. 19 Cyclopean Cannibalism prototype wall

important, not only in ensuring drafts angles which allow parts to be set, but that the assembly can be stable throughout the construction process. The recipe is linear and progressive, imparting a design process that ensures the assembly process will be both geometrically possible as well as physically stable. Once this virtual set algorithm is complete, the units are ready to be carved.

\section{Carving}

These units are carved with a six-axis robotic arm in conjunction with an external rotary table. Each unit is set on the rotary table with the flat back side down. This surface is left planar and not carved. The remaining geometries to be carved include the side faces and the front dressed face. The majority of the side faces are planar and intersect with obtuse angles. These are through-cut rapidly with a saw. In the event of a Utah detail, interior corners are produced, requiring a contour milling operation. In order to expedite this process, these faces are carved with "swarf" machining. This process of carving can be seen as a tilted profile cutting a ruled surface and therefore establishes the bounding conditions of each of the units and how these units rest upon each other. Figure 16 describes this process.

Once these side edges are carved, the units still retain their original stock thickness. The back faces of the assembly are planar, and therefore slip past each other, they do not serve as an index for the placement of stones. The fronts also 
Fig. 20 Detail of the front dressed face

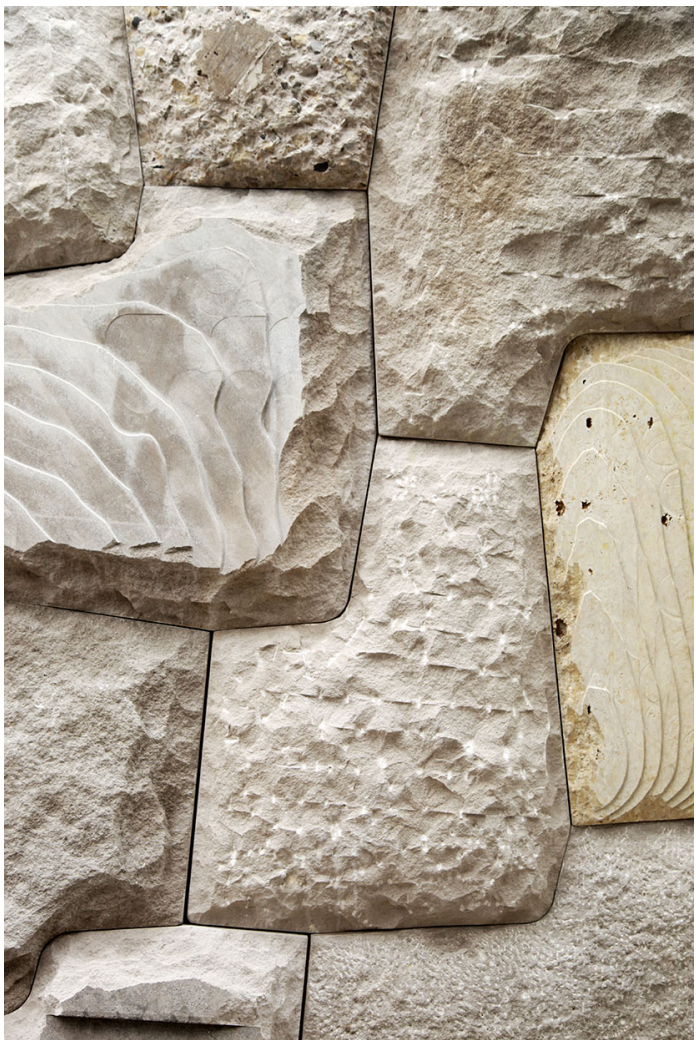

operate from a variable stock dimension, meaning their depths needs to be carved back to index how each unit can be set relative to its neighbors. In order to index this depth, the primary global geometry is intersected with the edge surfaces to produce a curve that brings the variable thickness of these rubble stones back to the global surface geometry. While on the robotic table, a milling bit traces this curve onto the side faces of the part. The part is then removed from the table and hand worked to rapidly dress this thick volume back to this complex edge geometry. This process of pitching is rapid and large chunks of excess material are removed while this precise edge is maintained. The result is a rough pillowing to this dressed face which is reminiscent of the original cyclopean masonry walls as seen in Fig. 17.

One of the challenges in working with massive stones is the assembly process. The prototype wall was assembled by a team of unskilled laborers, guided by the recipe, which dictates the order that assembly must follow. The wall is designed to be stable once assembled, but the stones must be guided precisely in order slide vertically into place. In some cases, the orientation of a "lifted stone" did not match its final orientation due to the relationship of the pick points and the center of gravity. This should be considered in future iterations of the process. In the case of the prototype, the stones were dry stacked, in order to produce a structure that could be disassembled. This necessitated the use of structural alignment dowels across the 
Fig. 21 Detail of the back planar surface
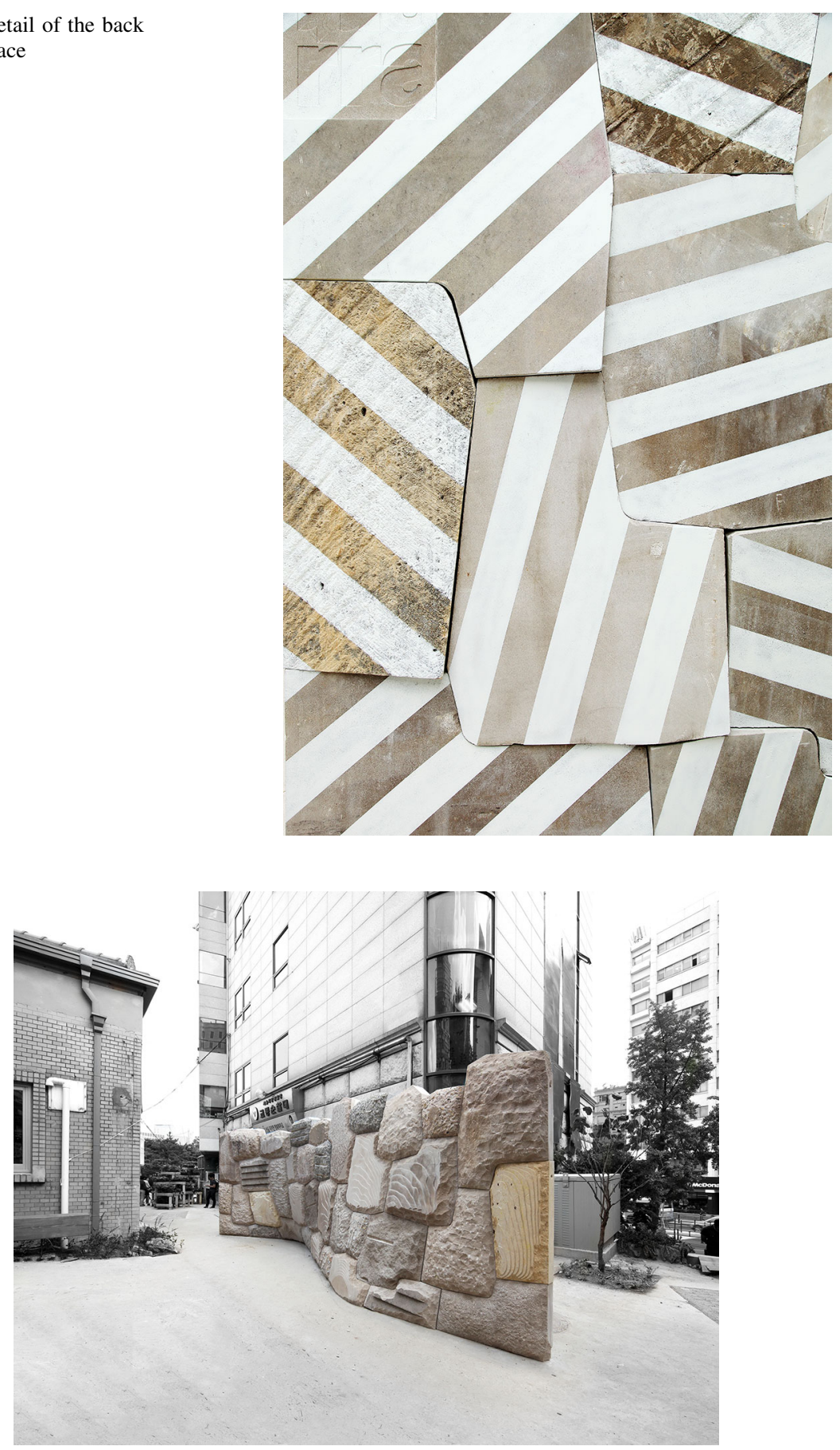

Fig. 22 Cyclopean Cannibalism prototype wall 


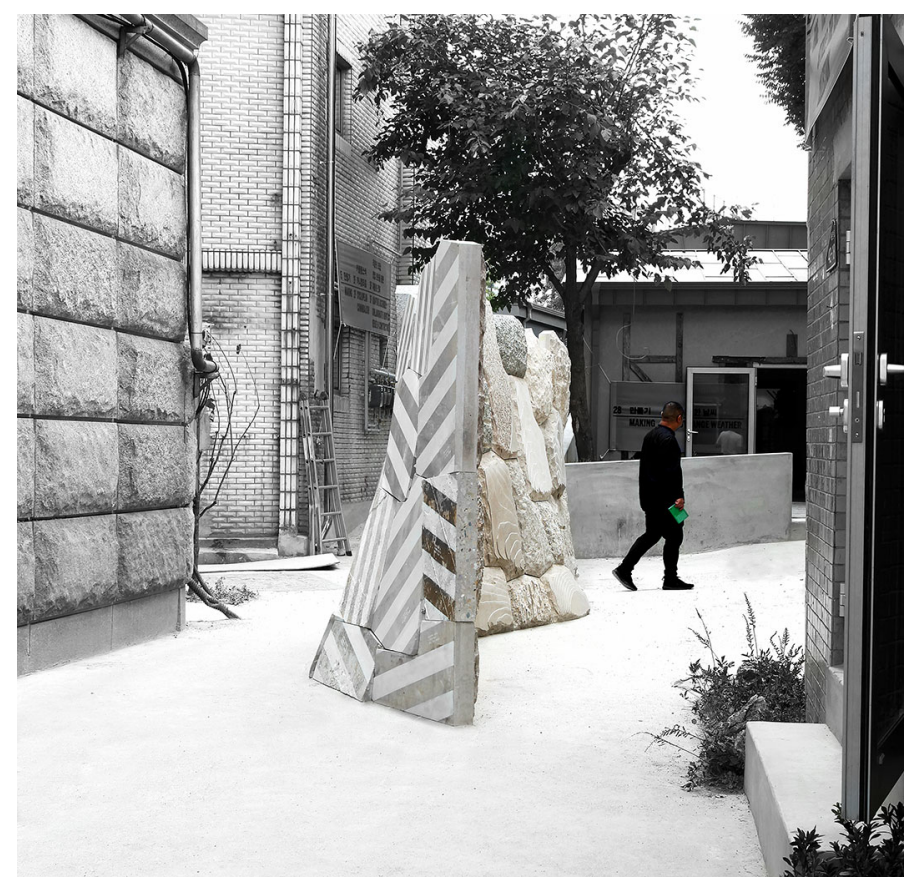

Fig. 23 Cyclopean Cannibalism prototype wall

joints. The demand for precision in the placement of these holes is critical, and they must be aligned according to the vector along which the massive stones will be lowered into place (Figs. 18, 19, 20, 21, 22, 23).

\section{Conclusion}

The Cyclopean Cannibalism wall prototype is the first of many tests to implement the theoretical recipes put forth in the Cannibal's Cookbook. The intention behind this work is to disseminate the potentials of this way of thinking in the digital context. The technique intends to be accessible for a broad audience, to combat the increasing urgency of building waste generation. In addition to these contributions, contemporary building practices as they relate to waste production are cast in a new light.

The Cyclopean Cannibalism wall prototype yielded $73 \%$ of the scanned stock material. While this number could be improved upon with a larger sampling, that percentage constitutes $100 \%$ of discarded rubble. This prototype demonstrates the viability of digitizing the cannibalistic process of cyclopean construction, but also raises a number of questions regarding what content should be carried over into the digital era. For instance, while the Inka were operating under a procedural rule-set, their constructions were built from the ground up, stone by stone, without a predetermined composition. On the other hand, Cyclopean Cannibalism employed 
digital procedures to run the same recipes (or codes) but through a virtual set. In this process, the entire wall is established digitally and each stone is custom carved to assemble together. This process does not take into account accretion of tolerance errors, or if a stone might crack in the process of setting. Therefore, further work could integrate this knowledge back into the algorithm.

With this approach to design, materiality, and fabrication, stone works become both resource and resolution. By embracing discarded values of implausibility, we re-engage lost topics that surround volumes. The more the practice experiments through these means, the more value we find in the unexpected-the mythical, the fantastic, the illogical.

Acknowledgements This research is funded by the Massachusetts Institute of Technology with support from the MIT Sloan Latin America Office, the MIT HASS Fund, and the Marion and Jasper Whiting Foundation. The prototype is designed by Matter Design and realized by Quarra Stone Company. All figures are provided by the authors.

\section{References}

Clifford, B. 2017. The Cannibal's Cookbook: Mining Myths of Cyclopean Constructions. Boston, MA: Matter Publishing.

Clifford, B. and W. McGee. 2014. La Voûte de LeFevre: a Variable-Volume Compression-Only Vault. In: FABRICATE: Negotiating Design \& Making. Zurich: gta Verlag: 146-153.

Clifford, B. and W. McGee. 2017. Cyclopean Cannibalism, or, Taming Rubble with Robots. In: Imminent Commons: The Expanded City, eds. Alejandro Zaera-Polo \& Jeffrey S. Anderson, New York: Actar Publishers: 307-321.

Dal Mutto, C., P. Zanuttigh and G. Cortelazzo. 2012. Time-of-Flight Cameras and Microsoft Kinect ${ }^{\mathrm{TM}}$. SpringerBriefs in Electrical and Computer Engineering.

Dean, C. 2010. A Culture of Stone: Inka Perspectives on Rock. Durham, NC: Duke UP.

Dorfler, K., T. Sandy, M. Giftthaler, G. Gramazio, M. Kohler and J. Buchli. 2016. Mobile Robotic Brickwork: Automation of a Discrete Robotic Fabrication Process Using an Autonomous Mobile Robot. In: Robotic Fabrication in Architecture, Art and Design: 204-2017.

Harvey, D. 2014. The Crisis of Planetary Urbanization. Uneven Growth: Tactical Urbanisms for Expanding Megacities. The Museum of Modern Art: New York.

Helm, V., S. Ercan, F. Gramazio, and M. Kohler. 2012. Mobile robotic fabrication on construction sites: DimRob. In: Intelligent Robots and Systems (IROS), 2012 IEEE/RSJ International Conference on Intelligent Robots and Systems, 4335(4341). Vilamoura, Portugal: IEEE.

Hesiod. 1953. Theogony (c. 700 BCE). Ed. Norman Brown. New York: Liberal Arts.

Hoornweg, D., P. Bhada-Tata, and C. Kennedy. 2013. Environment: Waste Production Must Peak This Century. Nature 502(7473): 615.

Hopkins, K. and M. Beard. 2005. The Colosseum. Cambridge, MA: Harvard University Press.

Lynn, G. 2005. Blob Wall. http://glform.com/environments/blobwall/ (accessed 29 April 2018).

Protzen, J. 1993. Inca Architecture and Construction at Ollantaytambo. New York: Oxford University Press.

U.S. EPA. 2016. Construction and Demolition Debris Generation in the United States, 2014. https:// www.epa.gov/sites/production/files/2016-12/documents/construction_and_demolition_debris_ generation_2014_11302016_508.pdf (accessed 29 April 2018).

U.S. EPA. 2015. Municipal solid waste generation, recycling, and disposal in the United States: Facts and Figures. https://www.epa.gov/sites/production/files/2015-12/documents/methodolgy_ document_for_selected_municipal_solid_waste_products.pdf (accessed 29 April 2018).

Vasey, L., I. Maxwell and D. Pigram. 2014. Adaptive Part Variation: A Near Real-Time Approach to Construction Tolerances. In: Robotic Fabrication in Architecture, Art and Design: 291-304.

Woods, L. 1997. Radical Reconstruction. Princeton, NJ: Princeton Architectural Press. 
Zaera-Polo, A. and J. Anderson. 2017. Imminent Commons: The Expanded City. New York: Actar Publishers.

Brandon Clifford is an Assistant Professor at the Massachusetts Institute of Technology and Principal at Matter Design, an architectural research laboratory. Brandon received his Master of Architecture from Princeton University in 2011 and Bachelor of Science in Architecture from Georgia Tech in 2006. He worked as project manager at Office dA from 2006 to 2009, LeFevre Fellow at OSU from 2011 to 2012, and Belluschi Lecturer at MIT from 2012 to 2016. Brandon has been awarded the Rome Prize, Design Biennial Boston Award, the Architectural League Prize, as well as the prestigious SOM Prize. Brandon's translation of past knowledge into contemporary practice continues to provoke new directions for digital design.

Wes McGee is an Assistant Professor and the Director of the FABLab at the University of Michigan Taubman College of Architecture and Urban Planning, and a Principal at Matter Design. He received a Bachelor of Science in Mechanical Engineering and a Masters in Industrial Design from the Georgia Institute of Technology. His work revolves around the interrogation of the means and methods of material production in the digital era, through research focused on developing new connections between design, engineering, materials, and manufacturing processes as they relate to the built environment. With the goal of seamlessly integrating critical feedback between fabrication constraints and design intent, the work spans multiple realms, including algorithmic design, computational modeling of material behaviors, industrial control technologies, and the development of novel production processes which utilize industrial robots as bespoken machines of architectural production.

Mackenzie Muhonen is a researcher at Matter Design. She is currently a graduate student at MIT (M.Arch 2019). She received her Bachelor of Arts in History and Spanish/Portuguese from University of California, Berkeley in 2013. Mackenzie has been awarded a Fulbright Fellowship (2014) and more recently the Kohn Pedersen Fox Travelling Fellowship (2018). 